\title{
Exteriorization of uterus before placental expulsion and intra-myometrial oxytocin versus in situ repair and IV oxytocin during LSCS - A comparative study
}

\author{
Sahadev Sahoo ${ }^{1}$, Debraj Mondal',*, Amar Nath Gupta ${ }^{3}$, Ajit Ranjan Bhattacharya ${ }^{4}$ \\ ${ }^{1}$ Associate Professor, ${ }^{2,3}$ Assistant Professor, ${ }^{4}$ Professor \& HOD, ${ }^{1,2,4}$ Dept. of Obstetrics and Gynecology, ${ }^{3}$ Dept. of \\ Anaesthesiology, Gouri Devi Intitute of Medical Sciences and Hospital, Durgapur, West Bengal, India
}

*Corresponding Author:

Email: dr.debrajmondal@gmail.com

\begin{abstract}
Introduction: A suitable modification of any step of caesarean section to reduce blood-loss should be considered as the morbidity and mortality of CS is mostly associated with excessive hemorrhage.

Aim: This is a comparative study of uterine exteriorization and intra-myometrial (IMM) oxytocin 5 IU before placental expulsion with conventional method of intra-abdominal repair with 10 IU IV oxytocin with primary objective to compare the blood-loss.

Materials and Methods: A prospective study of 2 groups, 100 women in each group (Primis \& $2^{\text {nd }}$ gravidas between 19-34 years of age) having hemoglobin above $10 \mathrm{gm} \%$ in cephalic presentation with almost identical indications for CS excluding prematurity, APH, IUGR, bleeding disorders, fibroids etc.

Standard caesarean procedure followed except exteriorization of uterus before placenta delivery and IMM oxytocin 5 IU in Gr1; and intra-abdominal repair and slow IV $10 \mathrm{IU}$ oxytocin in Gr2. Preoperative, Postoperative and difference of $\mathrm{Hb}$, duration of surgery from baby birth to starting of abdominal closure, blood-loss by volumetric method noted and compared after mean calculation by student $\mathrm{t}$ and chi-square test. Intra-operative and post-operative complications compared by relative risk calculation.

Results: The values of postoperative $\mathrm{Hb}$ level 99.2 against $89.2 \mathrm{~g} / \mathrm{l}$, Hb difference between pre- and postoperative level 12.7 against $23.2 \mathrm{~g} / \mathrm{l}$, blood loss $394.8 \mathrm{ml}$ against $461.6 \mathrm{ml}$, duration of surgery $11 \mathrm{~min} 10 \mathrm{sec}$ against 19 min 53 sec were highly significant $(\mathrm{p}<0.0001$ by student $\mathrm{t}$ and chi square test). The hospital stay with relative risk calculation shows significant difference between 2 groups.

Conclusion: Exteriorization of uterus before placental separation and IMM oxytocin reduces not only blood loss and time taken in caesarean sections, also the hospital stay.
\end{abstract}

Keywords: Exteriorization. IMM oxytocin. Placental expulsion. Hospital stay.

\section{Introduction}

Various techniques are advocated for the steps of caesarean section to make the surgery easy, convenient and advantageous. A scientific approach modifying any part of the procedure can have wide spread implication as this is the commonest major surgery on women, more than 20 million cases being performed globally every year USA contributing 12.5 million. PPH occurs more often in emergency caesarean sections. The morbidity and mortality of CS is mostly associated with excessive hemorrhage mainly from placental site due to uterine atony. ${ }^{1-4}$ There is room for innovation in this surgical component that can also minimize hospital stay without compromising the safety profile. Saving operating time is an additional advantage.

\section{Review of Literature}

Uterine Exteriorization compared with in situ repair for Cesarean delivery: a systematic review and meta-analysis including sixteen studies and 9736 women undergoing exteriorization concluded it may reduce blood loss and associated decrease in haemoglobin though the difference may not be clinically relevant. There is no statistically significant difference regarding intra-operative nausea, vomiting. ${ }^{5}$ Surgical time is also shorter in extra- abdominal repair. ${ }^{6}$
Post-operative febrile morbidity was lower with relative risk of 0.41 in patients undergoing eventration of uterus. Exteriorization of uterus is a valid option, as demonstrated by clinical and statistical evidence. ${ }^{7,8}$ An alternative surgical sequence of delivering the placenta in the exteriorized uterus with IMM oxytocin showing statistically significant decrease in blood loss seems to be physiologically sound procedure with significant decrease in operative time. ${ }^{9}$ There was statistically no significant difference between the two groups as far as intra-operative nausea, vomiting is concerned. ${ }^{5,7}$ Blood loss is significantly more in the non- eventrated group; uterine eventration at caesarean section is not to be condemned. ${ }^{10}$

For active management of the $3^{\text {rd }}$ stage of labour WHO recommended uterotonics before placental delivery in all cases to prevent PPH. Oxytocin as the $1^{\text {st }}$ line drug in a dose of $10 \mathrm{IU}, \mathrm{IV} / \mathrm{IM}$ is recommended. $\mathrm{CCT}$ is the recommended method for placental removal in all cases of caesarean sections. Sustained uterine massage is not recommended to prevent PPH in those who have received prophylactic oxytocin, but uterine tonus assessment for early identification of uterine atony is recommended for all women. ${ }^{11}$

Prophylactic intra-myometrial oxytocin before placental delivery in caesarean section in lesser dose of 5 IU is more effective to control PPH than the 
recommended $10 \mathrm{IU}$ IV/IM and the systemic sideeffects like tachycardia, lowering of B.P., nausea \& vomiting are less. ${ }^{12}$

Uterine exteriorization before separation of placenta and intra-myometrial oxytocin and repair outside the abdomen has been tried and benefits as regards less bleeding and lesser fall in $\mathrm{Hb}$ has been documented with advantage of lesser days of hospital stay without any difference in adverse effects. ${ }^{9}$

A prospective comparative study was conducted in Gouri Devi institute of Medical Sciences \& Hospital, Durgapur, West Bengal after permission from ethical committee and obtaining written consents from patients from Jan.2016 to Mar. 2017 combining all three i.e. exteriorization, IMM oxytocin and timing of exteriorization before placenta delivery.

\section{Aims and Objectives}

To compare the effects of uterine exteriorization and oxytocin 5 IU IMM before expulsion of placenta with intra-abdominal repair of uterine incision and oxytocin 10 IU IV during CS.

\section{Materials and Methods}

Only primis (G1P0A0) between 19-29 years and second gravidas with previous vaginal delivery with one or no living child (G2 P1 L1 A0/ G2P1L0A0) between 19 and 34 years of age, with $\mathrm{Hb}>10 \mathrm{~g} \%$, gestational age by LMP and USG > 37 weeks, in cephalic presentation, before or during labour and done under spinal anaesthesia; 100 cases in study group (Gr1) and 100 in control group (Gr2).

Exclusion Criteria: Primis below 19 and above 29, $2^{\text {nd }}$ gravidas above 34 years of age, gravida above $3, \mathrm{Hb}$ level less than 10 gram\%., h/o miscarriage, multiple pregnancy, IUGR, prematurity, placenta praevia, where placenta encountered at the site of incision, accidental haemorrhage, presentations other than cephalic, previous CS, failed instrumental delivery, bleeding disorders, low platelet count, eclampsia, medical disorders, intra-abdominal adhesion making exteriorization difficult, uterine fibroids and where general anaesthesia given.

In Group 1 just after delivery of baby the uterus with placenta exteriorized, 5 IU oxytocin administered IMM with thin-bore needle (24 size) by $2-3$ pricks without dilution, placenta delivered by CCT and uterus repaired on anterior abdominal wall. In Group2 oxytocin $10 \mathrm{IU}$ given slow IV within 2 minutes as a bolus after baby delivery, placenta delivered by CCT and uterine incision repaired inside abdomen i.e. conventional method. In both groups 20 IU oxytocin in a pint of Ringer's lactate started IV drip after baby delivery.

Manual removal of placenta (MRP) resorted to when required. Extension of uterine incision, any excessive hemorrhage taken care of with supplementation of suitable uterotonics, blood transfusion, uterine embracing procedure (B-Lynch) if needed and abdomen closed with or without peritoneal closure as per choice of the surgeon. Time from baby delivery to starting abdominal closure or parietal peritoneal closure is noted as $\mathrm{T} 1$ for $\mathrm{Gr} 1 \& \mathrm{~T} 2$ for $\mathrm{Gr} 2$.

The Gr1 is conducted by the author with his team and $\mathrm{Gr} 2$ by other 5 gynecologists who followed the conventional method but participated in the study for estimating the amount of blood loss and time for surgery.

Patients of each group were matched one-to-one regarding age, parity, gravidity, urgency status for CS and indication for CS in that order as far as practicable. The indications of caesarean section included one or more of the following:

Prolonged labour, primigravida with non-engaged head nearing full-term with USG estimation of fetal weight $>3.5 \mathrm{~kg}$, PROM, Oligohydramnios with AFI < $4 \mathrm{~cm}$., fetal distress, $\mathrm{BOH}$, post -dated pregnancy, and CS on request at full term - shown in TABLE-1

The standard procedure of LSCS with Pfannenstiel incision is followed with major variation regarding intra or extra abdominal uterine repair and route and dose of oxytocin; the exteriorization being done just after baby delivery.

Estimation of blood loss (EBS) was done by volumetric method. Separate soaking materials (gauge, tetra, pack) pre-soaked with normal saline and sqeezed and 2 suction machines - one for blood, another for amniotic fluid used. Materials used to soak blood from abdomen and vagina are sqeezed into a graduated jar containing 2 litres clean boiled water and the amount over and above 2litres drained into another long cylindrical graduated jar. The blood in the suction tube $\&$ suction bottle diluted with 2 litres of boiled cooled water and amount in excess of 2 litres added into the same cylindrical jar to know the total blood loss. To this, $50 \%$ is added as loss due to evaporation and noted as B1 for Gr1andB2 for Gr2. The ideal photometry and alkaline hematin methods being impracticable are not utilised. ${ }^{13,14}$

The change in $\mathrm{Hb}$ level is the difference between the preoperative $\mathrm{Hb}$ done within $24 \mathrm{hrs}$ before the operation and the postoperative day-2 level per litre of blood. The time taken from baby delivery to starting closure (T1 \& T2) and amount of blood-loss (B1 \& B2) recorded in TABLE 2.

Un-toward effects during surgery like nausea, vomiting, need for medication, pulse rate variation $(>20 /$ min), mean B.P. variation $(<20 \mathrm{~mm} \mathrm{Hg})$ and fall in $\mathrm{PaO} 2(<90 \%)$ are noted. Need for B.T. by noting blood loss and vital signs during operation \& Hb difference $>$ $2 \mathrm{~g} \%$ postoperative, febrile period $>2$ days, hospital stay $>5$ days after surgery recorded in TABLE 3 .

Intra-operative events after baby delivery like PPH, cases requiring MRP, need for uterine embrassing procedure, need for caesarean hysterectomy noted in TABLE 4. 


\section{Result}

Group 1 comprises of 78 cases of G1 P0 A0 in the age group19-29 years and 22 cases of G2 P1 L1/0 A0 in the age group of 19-34 years - total no. 100. Group2 comprises of 74 cases of $\mathrm{G} 1 \mathrm{P} 0 \mathrm{~A} 0$ in the age group of 19 - 29 years and 26 cases of G2 P1 L1/0 A0 in the age group of 19 - 34 years -total 100 cases.

In the Gr1 CS has been conducted on 15 patients before the onset of laour (11 primis and $4-2^{\text {nd }}$ gravidas), in $\mathrm{Gr} 2$ on 14 patients before onset of labour (11 primi and 3- $2^{\text {nd }}$ gravidas). The rest were in labour.

There were multiple indications in some, the main indication is mentioned. For post-dated pregnancy 5 cases have been included in each group all primis in 1929 age group. The other indications like oligohydramnios, PROM, BOH, fetal distress and onrequest have automatically fallen in almost identical numbers.

$\mathrm{Hb}$ levels (TABLE 2) shows no significant difference in preoperative level; but the difference is highly significant in the postoperative levels and the difference in $\mathrm{Hb}$ levels in 2 groups $(\mathrm{p}<0.0001)$. The mean time T1 is 11 min. 10 seconds with SD 4 min 3 seconds and T2 is 19 min. 53 seconds with SD 4 min. 25 seconds is highly significant. The mean blood loss B1 is $394.8 \mathrm{ml}$ (SD $117.1 \mathrm{ml}$ ) and B2 is $461.6 \mathrm{ml}$ (SD106.5 ml) - difference is highly significant. Cheng Wei Xiao et al reported the blood loss was $531 \mathrm{ml}$ (SD 184.1) and 691ml (SD 222.2) respectively. ${ }^{9}$ The smaller SD in our study may be due to its bigger size, exclusion criteria and more identical inclusions of clinical significance. The smaller mean blood loss may be due to lower BMI in our patients. The $\mathrm{Hb}$ difference is 12.7(5.3) and 23.2(7.5) g/l in our study which is 13.2 (6.2) and 16.9 (7.9) respectively in their study; may be because we have taken the $\mathrm{Hb}$ values on postoperative day 2 instead of day1, indicating that lochia rubra is more in $\mathrm{Gr} 2$ patients.

The un-toward effects like pulse rate variation $(>20 / \mathrm{min})$, variation in mean B.P. variation $(<20 \mathrm{~mm}$ of $\mathrm{Hg})$ and $\mathrm{pO} 2(<90 \%)$ which are 5,3,4 patients in Group1 and 8,6 and 5 patients in Group2 respectively. There is no condition requiring extra medication in any case. The relative risks calculation shows no significant difference. Though it is seen that the need for BT, febrile days \& hospital stay are more in Gr2, relative risk calculation shows 'hospital stay' is significantly high in Gr2. TABLE 3

The complications encountered during CS TABLE 4 shows that MRP has been done more often in Gr2 i.e.16 cases as compared to 10 in Gr1. Similarly primary PPH encountered is more in $\mathrm{Gr} 2$ than in $\mathrm{Gr} 1$ i.e. 12 compared to 7 respectively. Need for BT is also more in $\mathrm{Gr} 2$ i.e. 14 compared to 10 in Gr1. Embracing procedures like B-Lynch has been done once in each group and there was no necessity of caesarean hysterectomy in any group. Relative risk calculation shows no significant difference.

Table 1: Showing selection of Cases

\begin{tabular}{|l|c|c|}
\hline \multicolumn{1}{|c|}{ Age \& Parity } & Group 1 (n=100) & Group 2 (n=100) \\
\hline 19-29 yr-all G1P0A0 & 78 & 74 \\
\hline 19-34 yr-all G2P1L1A0/G2P1L0A0 & 22 & 26 \\
\hline Gestational Age & & \\
\hline $37-40 \mathrm{wk}$ & 95 & 95 \\
\hline$>40 \mathrm{wk}$ & 5 & 5 \\
\hline Labour Status & & 86 \\
\hline In Labour & 85 & 14 \\
\hline Not in active Labour & 15 & \\
\hline Indications for CS & & 34 \\
\hline Prolonged Labour & 31 & 19 \\
\hline Cephalo-pelvic disproportion & 21 & 7 \\
\hline PROM & 8 & 10 \\
\hline Oligo-hydramnios & 9 & 8 \\
\hline Bad Obstetric Hisptory & 9 & 5 \\
\hline Post dated pregnancy & 5 & 13 \\
\hline Fetal distress & 12 & 4 \\
\hline CS on request & 5 & \\
\hline
\end{tabular}


Table 2: Outcomes

*T test

\begin{tabular}{|l|c|c|c|c|}
\hline \multicolumn{1}{|c|}{ Primary } & $\begin{array}{c}\text { Group 1 } \\
\text { Mean (SD) }\end{array}$ & $\begin{array}{c}\text { Group 2 Mean } \\
\text { (SD) }\end{array}$ & *P-value & Significance \\
\hline Pre-op Hb & $112.27(5.78)$ & $112.36(5.51)$ & 0.91 & NS \\
\hline Post-op Hb & $99.26(5.17)$ & $89.24(7.27)$ & $<0.0001$ & Significant \\
\hline Hb changes & $12.77(5.34)$ & $23.21(7.54)$ & $<0.0001$ & Significant \\
\hline $\begin{array}{l}\text { Estimated } \\
\text { Blood Loss (ml) }\end{array}$ & 394.85 & $461.65(106.5)$ & $<0.0001$ & Significant \\
\hline \multicolumn{1}{|c|}{ Secondary } & $(117.1)$ & & & \\
\hline $\begin{array}{l}\text { Operating time } \\
\text { (Min) }\end{array}$ & $\begin{array}{c}11 \mathrm{~min} 10 \mathrm{sec} \\
(4 \mathrm{~min} 03 \mathrm{sec})\end{array}$ & $\begin{array}{c}19 \min 53 \mathrm{sec}(4 \\
\min 25 \mathrm{sec})\end{array}$ & $<0.0001$ & Significant \\
\hline
\end{tabular}

Table 3: Showing complications

\begin{tabular}{|l|c|c|c|c|}
\hline $\begin{array}{c}\text { Untoward affects } \\
\text { during CS }\end{array}$ & $\begin{array}{c}\text { Group 1 } \\
\text { n (\%) }\end{array}$ & $\begin{array}{c}\text { Group 2 } \\
\text { n (\%) }\end{array}$ & $\begin{array}{c}\text { *P-value } \\
\text { (Relative risk) }\end{array}$ & Significance \\
\hline Nausea/vomiting & 5 & 7 & 0.55 & NS \\
\hline $\begin{array}{l}\text { Pulse rate variation } \\
(>20 / \text { min) }\end{array}$ & 5 & 8 & 0.39 & NS \\
\hline $\begin{array}{l}\text { Mean BP variation } \\
(>20 \mathrm{mmHg})\end{array}$ & 3 & 6 & 0.32 & NS \\
\hline PaO2 <90\% & 4 & 5 & 0.73 & NS \\
\hline $\begin{array}{l}\text { Any problem needing } \\
\text { extra medication }\end{array}$ & Nil & Nil & -- & -- \\
\hline $\begin{array}{l}\text { Post op } \\
\text { Complications blood }\end{array}$ & $10(10 \%)$ & $14(14 \%)$ & 0.387 & NS \\
\hline $\begin{array}{l}\text { Need for bl } \\
\text { transfusion (Intra \& } \\
\text { Post operative) }\end{array}$ & $1(1 \%)$ & $7(7 \%)$ & 0.06 & Significant \\
\hline $\begin{array}{l}\text { Febrile conditions } \\
\text { (post op>2 days) }\end{array}$ & $1(1 \%)$ & $8(8 \%)$ & 0.04 & \\
\hline $\begin{array}{l}\text { Hospital stay (Post } \\
\text { op>5 days) }\end{array}$ & & & & \\
\hline
\end{tabular}

*Relative risk calculation assuming Group 1 as control for statistical purpose

Table 4: Complications encountered after baby delivery

\begin{tabular}{|l|c|c|c|c|}
\hline & $\begin{array}{c}\text { Group 1 } \\
\mathbf{n}(\%)\end{array}$ & $\begin{array}{c}\text { Group 2 } \\
\mathbf{n}(\%)\end{array}$ & $\begin{array}{c}* \text { P-value } \\
\text { (Relative risk) }\end{array}$ & Significance \\
\hline Requiring MRP** & $10(10 \%)$ & $16(16 \%)$ & 0.21 & NS \\
\hline $\begin{array}{l}\text { Extension of uterine } \\
\text { incision }\end{array}$ & $6(6 \%)$ & $5(5 \%)$ & 0.76 & NS \\
\hline $\begin{array}{l}\text { Primary PPH during } \\
\text { surgery }\end{array}$ & $7(7 \%)$ & $12(12 \%)$ & 0.24 & NS \\
\hline $\begin{array}{l}\text { Need for embracing } \\
\text { suture (B-Lynch) }\end{array}$ & $1(1 \%)$ & $1(1 \%)$ & 1.0 & NS \\
\hline $\begin{array}{l}\text { Need for } \\
\text { hysterectomy Nil }\end{array}$ & Nil & -- & -- \\
\hline
\end{tabular}

*Relative risk calculation assuming Group 1 as control for statistical purpose

***MRP- Manual removal of Placenta

\section{Discussion}

Surgical procedures play important role for desired outcomes and speedy recovery of patients by affecting the immediate blood loss and duration of surgery. Caesarean section has undergone changes in components like incision, dissection and suturing; but 
the placental delivery method remains mostly the same. ${ }^{9}$ Whether the uterus should be exteriorized or not is a subject of discussion for many years due to less number and smaller sizes of studies. ${ }^{16}$ The Cochrane review from 2005 to 2012 found no difference between extra-abdominal and intra-abdominal repair and left it to the surgeons' preference and viewed exteriorization as a valid option. The concept of exteriorizing the uterus just after the baby delivery before placental expulsion has evolved due the fact that placental delivery can be equally done in the exteriorized uterus and manipulations are easier, quicker and can be done within the half-life of oxytocin due to clean surgical field, less intra-abdominal handling is required and scope for other procedures like extension of uterine incision repair, embrassing procedures, hysterectomy is better. ${ }^{9,12,19}$ Febrile postoperative days and hospital stays are less.

From this study it is apparent that the postoperative $\mathrm{Hb}$ count is significantly less in the control group. The blood loss and operative time differences between the 2 groups are also highly significant. In this technique, after the baby delivery, instead of watching for uterine contraction for placental delivery we exteriorize the uterus - manipulation that stimulates the uterus, inject oxytocin in a smaller dose..$^{15}$ directly into myometrium which is the site of its action, ${ }^{17}$ clean the field and by this time the uterus is ready for CCT. If CCT is not successful, an early attempt for MRP can be done which curtails the placenta delivery time to the barest minimum. This also minimizes blood loss which is clinically negligible, but the expedient surgery saves times that is significant for a busy surgeon and OT. The exteriorized uterus remains in contact with our palms for detection of any flabbiness, and if detected suitable steps can be taken even before PPH starts.

With clean surgical field uterine repair is quicker. Originally exteriorization started to detect and repair for extended bleeding angles of uterine incisions. Quicker surgery saves blood loss. Doyen's retractor is sparingly used, thereby avoiding constant pressure over detrusor muscle minimizing urinary retention. Traction of anterior abdominal muscles and rectus sheath for abdominal exposure is unnecessary and they regain their tone earlier.

Intra-abdominal structures require less handling and peritoneum needs no rubbing to clear the blood as there is little blood inside. The only structure outside is the uterus which can also be covered by warm mob exposing only the lower segment. The 'interior milieu' which refers to the extra-cellular fluid environment and physiological protective stability for tissues inside abdomen - is better maintained due to less exposure as the exteriorized uterus immediately seals the abdomen from external environment. This explains quicker recovery, lesser febrile days and lesser hospital stay. Single layer peritoneal dehydration is less, hence less adhesion formation-a long-term advantage [18].
Concurrent sterilization, embrassing procedures, small myomectomy, hysterectomy if required, are comfortably done in exteriorized uterus.

The lesser frequency of nausea, vomiting, tachycardia, lowering of $\mathrm{O} 2$ saturation in the study group may be due to oxytocin dose of $5 \mathrm{IU}$ in place of $10 \mathrm{IU}$ in $\mathrm{Gr} 2$ - a big difference in dose, that too locally its half-life being only 2-6 minutes. ${ }^{15,19}$

\section{Conclusion}

Exteriorization of uterus before placental expulsion and oxytocin 5 IU IMM compared with intra-abdominal repair and $10 \mathrm{IU}$ IV is advantageous regarding blood loss, duration of surgery and hospital stay.

\section{Acknowledgement}

We are grateful to our Principal, GIMSH and ethical committee to allow this study and publish.

Funding or sponsorship: Nil

Conflict of interest: All authors declare to have no conflict of interest.

\section{References}

1. Ana Paula Esteves-Pereira1,2*, Catherine DeneuxTharaux1, Marcos Nakamura-Pereira2,3, Caesarean Delivery and Postpartum Maternal Mortality: A Population-Based Case Control Study in Brazil , Monica SPLOS ONE DOI:10.1371/journal.pone.0153396 April 13, 2016 aucedo1, Marie-Hélène Bouvier-Co

2. Carlos Montufar-Rueda, Laritza Rodriguez, José Douglas Jarquin, Alejandra Barboza, Maura Carolina Bustillo, Flor Marin, Guillermo Ortiz, and Francisco Estrada Severe Postpartum Hemorrhage from Uterine Atony: A Multicentric Study Journal of Pregnancy Volume 2013 (2013), Article ID 525914, 6 pages

3. Callaghan WM, Kuklina EV, Berg CJ. Trends in postpartum hemorrhage: United States, 1994-2006. Am J Obstet Gynecol 2010;202:353.e1

4. Bateman BT, Berman MF, Riley LE, Leffert LR The epidemiology of postpartum hemorrhage in a large, nationwide sample of deliveries. Anesth Analg. 2010;110(5):1368.

5. Zaphiratos V, George RB, Boyd JC, Habib AS Uterine exteriorization compared with in situ repair for Caesarean delivery: a systematic review and analusis. Can J Anaesth. 2015 Nov;62(11):1209-20. Doi: 10.1007/s12630-0150448-2. Epub 2015 Aug 22.

6. Coutinho IC, Ramos de Amorim MM at al Uterine exteriorization compared with in situ repair at caesarean delivery: a randomized control trial. Obstet Gynecol. 2008 Mar;111(3):639-47. Doi: 10.1097/AOG.0b013e31816521e2.

7. Cochrane Database of Systematic Reviews, Issue 1, 2009. DOI: 10.1002/14651858.CD000085.pub2 Extraabdominal versus intra-abdominal repair at caesarean section

8. Wilkinson C, Enkin MW Uterine exteriorization versus intraperitoneal repair at caesarean section. Cochrane Database Syst Rev. 2004

9. Cheng Wel Xiao, MD, Allan B. Climan et al. The Effect on Perioperative Bleeding of placental Extraction From an Exteriorized Uterus During Caesarean Section J Obstey Gynecol Can 2014;36(5):384-90. 
10. Hershey DW, Quilligan EJ Extraabdominal uterine exteriorization at caesarean section. Obstet Gynecol. 1978 Aug;52(2):189-92.

11. WHO recommendations for the prevention of postpartum haemorrhage. 2012. WHO: Geneva. Switzerland.

12. Divya Mangla, JK Goel et al Prophylactic Intramyometrial oxytocin before placenta delivery during Caesarean Section Prevents Postpartum Hemorrhage: A Prospective Randomized Study of 150 Women Journal of South Asian Federation of Obstetrics and Gynaecology. May-August 2012;4(2):93-6

13. Sahar V. Doctorvaladan, MD, Andrea T. Jelks, MD, Eric W. Hsieh, BS, Robert L. Thurer, MD, Mark I. Zakowski, MD, and David C. Lagrew, MDAccuracy of Blood Loss Measurement during Cesarean DeliveryAJP Rep. 2017 Apr; 7(2): e93-e100.doi: 10.1055/s-0037-1601382

14. Movis N. Schorn, CNM, PhD Measurement of Blood Loss: Review of Literature J Midwifery Women's Health. 2010,55(1)20-27 2010 Elsevier Science, Inc

15. Eduardo Tsuyoshi, TSA, MD.; Marcelo Luis Abramides Torres, TSA, MD Oxytocin in Cesarean Sections. What is the Best Way to Use It Revista Brasileira de Anestesiologia Vol. 57. No 3. Maio-Junho. 2007

16. Jacobs-Jokhan D, Hofmeyr GJ Extra-abdominal versus intra-abdominal repair of the uterine incision at caesarean section(Review) The Cochrane collaboration and published in The Cochrane Library 2007, Issue 4

17. Westhoff G, Cotter AM, Tolosa JE Prophylactic oxytocin for the third stage of labour to prevent postpartum haemorrhage. Cochrane Database Syst Rev. 2013

18. Cuschieri A., Buess G. (1992) Nature and scope of Endoscopic Surgery. In: Cuschieri A., Buess G., perissat J.(eds) Operative Manual of Endoscopic Surgery. Disadvantages of open surgery Springer, Berlin, Hedelsberg

19. Gunnar Ryden \& ingvar Sjoholm Half-life of Oxytocin in Blood of Pregnant and Non-pregnant women Pages 139-40 published on line: 09Jul2009. 